\title{
Investigasi Empirik Determinasi Beban Kerja dalam Meningkatkan Prestasi dan Produktivitas Kerja
}

\author{
Andi Riyanto ${ }^{1}$, Galih Raspati ${ }^{2}$, Agung Wibowo ${ }^{3}$, Amin Setio Lestiningsih ${ }^{4}$ \\ 1,3,4 Universitas Bina Sarana Informatika \\ Jl. Kramat Raya No.98, Senen, Jakarta Pusat 10450, Indonesia \\ ${ }^{3}$ STIE Pasim Sukabumi \\ Jl. Prana No. 8A Kota Sukabumi, Indonesia
}

e-mail: ${ }^{1}$ andi.iio@bsi.ac.id, ${ }^{2}$ galih_raspati@yahoo.com, ${ }^{3}$ agung.awo@bsi.ac.id, ${ }^{4}$ amin.asl@bsi.ac.id

\begin{tabular}{lll}
\hline Informasi Artikel Diterima: 10-06-2021 & Direvisi: 17-07-2021 & Disetujui: 22-07-2021 \\
\hline
\end{tabular}

\begin{abstract}
Abstrak
Beban kerja karyawan dan kompleksitas kerja merupakan salah satu fungsi dari struktur organisasi. Bahkan di dalam entitas yang sama, beban kerja karyawan berbeda-beda karena karyawan dengan peringkat yang sama mungkin beban kerjanya tidak sama. Dampak beban kerja yang tinggi dapat berpengaruh terhadap prestasi maupun produktivitas kerja karyawan itu sendiri yang efeknya terhadap target dan kebijakan operasional entitas. Riset ini bertujuan untuk melihat imbas beban kerja terhadap prestasi dan produktivitas kerja karyawan. Obyek penelitian adalah karyawan pada PT. Panjunan, Sukabumi. Sampel ditetapkan sebanyak 120 responden yang diperoleh dengan menggunakan teknik probability sampling. Metode penelitian deskriptif dengan pendekatan kuantitatif. Alat analisis menggunakan metode parsial yaitu untuk mencari hubungan antara dua variabel, di mana variabel lain yang dianggap berpengaruh dikendalikan atau tetap. Uji analisis instrumen penelitian menggunakan uji statistik dan hipotesis di uji dengan menggunakan pendekatan uji t dan uji F. Hasil penelitian menunjukkan beban kerja berdampak secara simultan terhadap prestasi dan produktivitas kerja dengan nilai dominan sebesar $87,8 \%$.
\end{abstract}

Kata Kunci: determinasi, beban kerja, prestasi kerja, produktivitas kerja.

\begin{abstract}
Employee workload and work complexity are functions of the organizational structure. Even within the same entity, different employee workloads due to employees with the same rank may not be the same workload. The impact of high workloads can affect the performance or work productivity of the employees themselves which have an effect on targets and operational policies of the entity. This research aims to see the impact of workload on employee performance and work productivity. Research objects are employees at PT. Panjunan, Sukabumi. The sample was determined as many as 120 respondents obtained using probability sampling techniques. Descriptive research method with a quantitative approach. The analysis test of the research instrument used statistical tests and the hypothesis was tested using the approach test and the F test. The results showed that workload had a simultaneous impact on work performance and productivity.
\end{abstract}

Keywords: determination, workload, work performance, work productivity.

\section{Pendahuluan}

Beban kerja yang ditanggung pekerja satu dengan yang lain tidaklah sama sebab tipe pekerjaan yang bermacam-macam. Besar rendahnya beban kerja bergantung dari tingkatan kompleksitas prosedur kerja, tuntutan kerja, tempo kerja, serta tanggung jawab pekerjaan. Masalah ini menimbulkan kecepatan dalam menuntaskan target serta produktivitas masing-masing pekerja yang tidak akan sama sesuai dengan beban masing-masing pekerja tersebut. Hal inilah yang terjadi selama ini pada PT. Panjunan sehingga mengakibatkan target penjualan tiap periode tidak tercapai secara maksimal.
Menurut (Golden, 2012) ketika jam kerja yang lebih lama menimbulkan beban kerja yang tinggi akan memiliki efek buruk pada tingkat kesehatan pekerja, karena kelelahan dan stres kerja sehingga mereka akan cenderung untuk berupaya mempertahankan produktivitas kerja di bawah potensinya."Terlalu banyak pekerjaan" dapat merujuk pada meningkatnya risiko yang akan dialami pekerja mengalami gejala kelelahan dan stres kerja, yang secara otomatis akan merusak prestasi kerja mereka baik secara jangka pendek atau jangka panjang sehingga akan menurunkan tingkat produktivitas kerjanya secara jangka panjang. 
Selain itu ada beberapa faktor yang memungkinkan produktifitas karyawan menurun selain dari pada beban target, yaitu tempo waktu, lingkungan kerja, dan juga cuaca, yang mengakibatkan tidak selalu tercapainya target penjualan para pekerja.

Fungsi kinerja disini adalah untuk memastikan jika aktivitas yang sudah dicapai oleh entitas tidak berubah dan telah sesuai dengan kebijakan perusahaan sehingga seluruh stakeholder ataupun proses dapat fokus pada linimasa pelayanan dan produk (Riyanto, 2019).

Berdasarkan observasi pada PT. Panjunan terdapat data target penjualan pada salah satu produk Bintang Toedjoe yaitu pada produk Komix Herbal selama satu tahun terakhir pada tahun 2020. Hal ini dapat dilihat dari tabel 1 .

Tabel 1. Laporan Realisasi Target Penjualan pada Produk Bintang Toedjoe Komix Herbal Tahun 2020

\begin{tabular}{ccccc}
\hline No & Bulan & $\begin{array}{c}\text { Target } \\
\text { Penjualan } \\
\text { Komix }\end{array}$ & $\begin{array}{c}\text { Realisasi } \\
\text { Pencapaian }\end{array}$ & Persentase \\
\hline 1 & Januari & 1.143 .000 & 747.000 & $65,3 \%$ \\
\hline 2 & Februari & 3.636 .000 & 1.097 .000 & $30,1 \%$ \\
\hline 3 & Maret & 1.657 .000 & 1.552 .000 & $93,6 \%$ \\
\hline 4 & April & 2.889 .000 & 1.096 .000 & $37,9 \%$ \\
\hline 5 & Mei & 2.503 .000 & 2.300 .000 & $91,8 \%$ \\
\hline 6 & Juni & 2.359 .000 & 2.115 .000 & $89,6 \%$ \\
\hline 7 & Juli & 2.377 .000 & 2.251 .000 & $94,6 \%$ \\
\hline 8 & Agustus & 2.800 .000 & 2.400 .000 & $85,7 \%$ \\
\hline 9 & September & 2.747 .000 & 2.320 .000 & $84,4 \%$ \\
\hline 10 & Oktober & 2.297 .000 & 1.857 .000 & $80,8 \%$ \\
\hline 11 & November & 2.423 .000 & 2.057 .000 & $84,8 \%$ \\
\hline 12 & Desember & 2.441 .000 & 2.127 .000 & $87,1 \%$ \\
\hline Sum
\end{tabular}

Sumber: Data target penjualan PT. Panjunan, 2020.

Data empiris pada tabel 1 menunjukan pencapaian target dan realisasi yang dihasilkan oleh karyawan sangat fluktuatif. Target dan realisasi yang merupakan hasil dari suatu pencapaian perusahaan pada PT. Panjunan masih kurang stabil. Hal tersebut mengindikasikan bahwa adanya pemberian beban kerja yang kurang sesuai dengan latar belakang pendidikan, keterampilan, pengalaman, dan waktu yang disediakan, sehingga target tidak tercapai dan produktivitas menurun.

Berdasarkan latar belakang penelitian diatas, maka rumusan masalah yang ditetapkan pada penelitian ini:

1. Bagaimana efek beban kerja terhadap prestasi kerja pada karyawan PT. Panjunan.

2. Bagaimana efek beban kerja terhadap produktivitas kerja pada karyawan PT. Panjunan.

3. Bagaimana efek beban kerja terhadap prestasi kerja dan produktivitas kerja pada karyawan PT. Panjunan.

Maksud dan tujuan dari penelitian ini:
1. Untuk mengetahui efek beban kerja terhadap prestasi kerja pada karyawan PT. Panjunan.

2. Untuk mengetahui efek beban kerja terhadap produktivitas pada karyawan PT. Panjunan.

3. Untuk mengetahui efek beban kerja terhadap prestasi kerja dan produktivitas kerja pada karyawan PT. Panjunan.

Beberapa penelitian yang selaras dengan penelitian ini antara lain hasil penelitian (Utami \& Magdalena, 2020) yang menyimpulkan beban kerja berdampak terhadap keputusan prestasi kerja dengan nilai koefisien regresi positif nilai t hitung sebesar 2,066 dengan nilai .sig sebesar 0,046. Begitupun dengan penelitian dari (Ariani, Ratnasari, \& Tanjung, 2020; Elvina, 2020) menyatakan produktivitas kerja dipengaruhi oleh beban kerja secara signifikan.

\section{Beban Kerja}

Beban kerja mencerminkan batas antara jumlah upaya fisik dan atau kognitif yang diperlukan untuk menyelesaikan tugas dan sumber daya, misalnya waktu, yang tersedia untuk digunakan pada tugas tersebut (Rosen et al., 2018). Beban kerja adalah apa yang dibutuhkan individu atau semua hal permintaan sistem pada individu yang diukur menggunakan teknik subjektif (laporan diri atau berdasarkan rating pengamat), berbasis kinerja dan teknis psikologi (Borghini, Astolfi, Vecchiato, Mattia, \& Babiloni, 2014). Beban kerja dapat diukur menggunakan basis kinerja berdasarkan asumsi bahwa manusia memiliki sumber daya yang terbatas, dan kinerja menurun saat tugas yang menuntut struktur sumber daya yang sama dibagi dengan waktu (Hsu et al., 2018); Yei-Yu Yeh \& Wickens, 1988). Jadi beban kerja merupakan permintaan sistem pada individu yang menggambarkan upaya fisik yang mentargetkan penyelesaian tugas berdasarkan waktu yang telah ditetapkan dan diukur berdasarkan basis kinerja.

Kebutuhan SDM bisa dihitung dengan mengidentifikasikan seberapa banyak output industri pada divisi tertentu yang akan diraih. Setelah itu diterjemahkan dalam wujud waktu (jam serta hari) karyawan yang dibutuhkan untuk menuntaskan output tersebut, sehingga diperoleh pada tipe pekerjaan apa saja yang terjalin deviasi negatif ataupun sesuai dengan standar yang dibutuhkan.Sedangkan analisis beban kerja adalah proses dalam menetapkan jumlah jam kerja sumber daya manusia yang bekerja, digunakan, dan dibutuhkan dalam menyelesaikan suatu pekerjaan untuk kurun waktu tertentu.

Dimensi dari beban kerja yaitu:

1. Beban kerja fisik yaitu beban kerja yang berdampak pada gangguan kesehatan seperti sistem pada tubuh, jantung, pernapasan, serta alat indera pada tubuh seseorang yang disebabkan oleh kondisi perkerjaan. Adapun indikator dari beban fisik yaitu: beban fisik fisikologis dan beban fisik biometika. 
2. Beban mental merupakan beban kerja yang timbul saat karyawan melakukan aktivitas mental atau psikis dilingkungan kerjanya. Adapun indikator dari beban mental yaitu: konsentrasi, adanya rasa bingung, kewaspadaan dan ketepatan pelayanan.

3. Beban waktu merupakan beban kerja yang timbul saat karyawan dituntut untuk menyelesaikan tugas-tugasnya sesuai dengan waktu yang telah ditentukan. Adapun indikator beban waktu yaitu: kecepatan dalam mengerjakan pekerjaan dan mengerjakan pekerjaan dua/lebih dalam waktu yang sama.

\section{Prestasi Kerja}

Prestasi kerja merupakan hasil yang dapat didemonstrasikan atau penampilan (appearance) karyawan (Sunarsi, 2020). Prestasi kerja juga digambarkan sebagai hasil dari kegiatan yang dilakukan oleh seseorang untuk orang lain untuk membantu orang tersebut melakukan pekerjaannya dengan lebih efektif dan atau untuk kemajuan dalam karirnya (James, Rayner, \& Bruno, 2015). Prestasi kerja adalah alat yang digunakan oleh organisasi untuk memelihara dan mengembangkan personelnya (Reza, Nugroho, \& Indonesia, 2020). Jadi prestasi kerja merupakan sebuah tools bagi entitas dalam mengukur kemampuan seseorang dalam melakukan pekerjaannya agar lebih efektif.

Manfaat menggunakan indikator prestasi kinerja diperlukan untuk meyakinkan pengambil keputusan dalam mengadopsi dan mendorong perubahan di tingkat organisasi (Gilson, Straker, \& Parry, 2012). Prestasi kerja dapat diprediksi lebih kuat oleh kesejahteraan umum daripada kepuasan kerja (Jaw, Po-Hsun Hsiao, Huan, \& Woodside, 2016).

Dimensi dari prestasi kerja yaitu:

1. Hasil kerja, tingkatan kuantitas ataupun mutu yang sudah dihasilkan serta sepanjang pengawasan dapat dilaksanakan.

2. Pengetahuan pekerjaan, tingkatan pengetahuan yang terpaut dengan tugas pekerjaan yang hendak mempengaruhi langsung terhadap kuantitas serta mutu dari hasil kerja.

3. Inisiatif, tingkat inisiatif dalam penugasan kerja terutama dalam menangani masalah yang muncul.

4. Kecekatan mental, kemampuan dan tingkat kecepatan untuk menerima instruksi kerja, menyesuaikan dengan gaya kerja dan kondisi kerja saat ini.

5. Sikap, semangat dan sikap positif saat mengerjakan tugas.

6. Disiplin waktu dan absensi, tepat waktu dan kehadiran.

\section{Produktivitas Kerja}

Memahami pengetahuan produktivitas kerja dan penggeraknya secara lebih komprehensif telah menjadi masalah yang cukup topikal karena konsep cara kerja yang baru (Palvalin, 2019).

Definisi produktivitas ini sangat dekat dengan konsep efisiensi, tetapi berbeda dengan kualitas hasil. Tetapi ada perbedaan antar konsep, di mana kinerja dapat dilihat sebagai istilah yang memayungi semua konsep yang melibatkan pemeriksaan terhadap keberhasilan organisasi. Produktivitas kerja diartikan sebagai produktivitas secara umum, tetapi pengetahuan tentang konteks kerja memberikan beberapa tantangan. Sifat pekerjaan adalah alasan terbesar mengapa konteks produktivitas tidak bisa diterapkan langsung dari manufaktur. Definisi produktivitas serupa, tetapi dalam kinerja, tantangan dimulai ketika input dan output harus diukur. Oleh karena itu, produktivitas kerja terbukti menjadi konteks yang menantang, dan banyak peneliti telah mencoba untuk memecahkan masalah tersebut (Koopmans et al., 2011; Laihonen, Jääskeläinen, Lönnqvist, \& Ruostela, 2012).

Dimensi dari produktivitas kerja karyawan yaitu:

1. Kemampuan, mempunyai kemampuan untuk melaksanakan tugas. Kemampuan karyawan sangat bergantung pada keterampilan dan tingkat profesional pekerjaan mereka. Ini memberikan keahlian untuk menyelesaikan tugas yang diberikan kepada mereka.

2. Meningkatkan hasil yang dicapai, berusaha untuk meningkatkan hasil yang dicapai. Hasilnya adalah mereka yang mengerjakan sesuatu dan mereka yang menikmati hasil kerja bisa merasakannya. Jadi, agar orang-orang yang terlibat dalam pekerjaan mampu menggunakan efisiensi kerja mereka.

3. Semangat kerja, ini merupakan upaya untuk menjadi lebih baik dari hari kemarin Indikator ini terlihat dari etika profesi kemudian dibandingkan dengan hari sebelumnya, yaitu hasil yang dicapai satu hari kemudian.

4. Pengembangan diri, mengembangkan diri secara terus menerus untuk meningkatkan kemampuan kerja dengan menghadapi tantangan dan harapan maka pengembangan diri dapat tercapai. Semakin kuat tantangan maka mutlak diperlukan pengembangan diri, demikian pula harapan yang lebih baik pada akhirnya akan sangat mempengaruhi keinginan karyawan untuk melakukan perbaikan.

5. Mutu, selalu berusaha meningkatkan mutu yang lebih baik daripada masa lalu. Mutu adalah hasil kerja yang menandakan kualitas kerja karyawan. Oleh karena itu peningkatan mutu bertujuan untuk memberikan hasil yang terbaik yang pada akhirnya akan sangat bermanfaat bagi perusahaan dan dirinya sendiri.

6. Efisiensi, bandingkan hasil yang diperoleh dengan total sumber daya yang digunakan. Input dan output merupakan bagian dari produktivitas yang berdampak signifikan terhadap karyawan. 


\section{Metode Penelitian \\ Rancangan Penelitian}

Metode yang digunakan dalam penelitian ini adalah metode penelitian deskriptif dengan pendekatan kuantitatif.

\section{Populasi dan Sampel}

Populasi dalam penelitian yaitu seluruh karyawan PT. Panjunan dengan jumlah sebanyak 172 orang karyawan.

Besarnya sampel ditentukan dengan pendekatan Yamane dan Isaac and Michael (Vashti \& Antonio, 2021) sebagai berikut:

$\mathrm{n}=\frac{N}{1+\mathrm{N}(e)^{2}}$

Keterangan:

$\mathrm{n}=$ Jumlah sampel minimal

$\mathrm{N}=$ Ukuran populasi

$\mathrm{e}=$ Tingkat kesalahan sampel (sampling error), presisi yang digunakan 5\% (0.05)

Maka:

$$
\frac{172}{1+172(0,05)^{2}}=\frac{172}{1,43}=120,27=120
$$

Berdasarkan pendekatan Yamane dan Isaac and Michael, sampel ditetapkan sebanyak 120 karyawan.

\section{Metode Pengumpulan Data}

Teknik pengumpulan data yang digunakan adalah kuesioner, yaitu metode pengumpulan data yang dilakukan dengan mengajukan lembaran angket yang berisi daftar pertanyaan yang harus diisi oleh responden yang akan dijadikan sampel dengan menggunakan skala likert sebagai dasar penilaian dan skala penilaian dari 1 sampai 5, gradasi penilaian sebagai berikut: sangat tidak setuju, tidak setuju, ragu-ragu, setuju dan setuju. Teknik ini dilakukan untuk mendapatkan data primer, yaitu data yang diperlukan secara langsung dari sumber penelitian itu sendiri.

\section{Uji Hipotesis}

Untuk melihat hubungan dari kedua jenis variabel yang diteliti yaitu variabel $\mathrm{X}$ dan variabel $\mathrm{Y}$, maka dilakukan pengujian hipotesis. Pada penelitian ini pengujian hipotesis statistik menggunakan uji $t$ dan uji F.

\section{Uji Validitas}

Pengujian validitas digunakan untuk mengukur alat ukur yang digunakan untuk mendapatkan data. Validitas instrumen fokus pada masalah sepanjang mana pengukuran sangat tepat dalam melakukan fungsi ukurnya (Yusup, 2018; Arifin, 2017).
Ketentuan minimum sebagai kriteria apabila $\mathrm{r}$ $\geq 0,3$ (Sugiyono, 2017). Jika korelasi antar item dengan skor total >0,3 maka instrumen tersebut dinyatakan tidak valid (Wahyuningrum, 2020).

\section{Uji Reliabilitas}

Instrumen yang valid serta reliabel akan menciptakan riset yang valid serta reliabel. Sebaliknya sesuatu instrumen yang memiliki faktor yang menyesatkan, akan menciptakan pula riset yang kurang baik (Ismunarti, Zainuri, Sugianto, \& Saputra, 2020). Setiap instrumen riset yang akan digunakan untuk mengumpulkan data perlu di uji validitas dan reliabilitasnya.

Pengujian reliabilitas konsisten internal dalam riset ini menggunakan koefisien Cronbach Alpha. Alasan penggunaan teknik ini, karena koefisien Cronbach Alpha merupakan indeks yang cukup sempurna dalam mengukur reliabilitas konsistensi antar butir. Kriteria empirik terhadap penilaian koefisien Cronbach Alpha adalah sebagai berikut:

Tabel 2. Kriteria Cronbach Alpha

\begin{tabular}{cc}
\hline Koefisien & Keterangan \\
\hline$\alpha<0,6$ & Kurang reliabel \\
$0,6<\alpha<0,8$ & Cukup reliabel \\
$\alpha>0,8$ & Sangat reliabel \\
\hline
\end{tabular}

(Noor, 2020)

\section{Uji Normalitas}

Distribusi normal merupakan fasilitas untuk menggapai tujuan yang bukan tujuan itu sendiri. Data terdistribusi secara normal dibutuhkan untuk mengaplikasikan beberapa tools statistik, seperti analisis regresi, uji t dan uji F (Sari, Sukestiyarno, \& Agoestanto, 2017).

Uji normalitas grafik normal $P-P$ plot of regression standardized residual merupakan salah satu cara untuk menguji normalitas residual.

\section{Uji Multikolinearitas}

Tujuan utama uji multikolinearitas adalah untuk menguji apakah dalam model regresi ditemui korelasi antara variabel independen. Apabila toleransi $>0,10$ serta nilai VIF $<10$ berarti tidak ada multikolinearitas, kebalikannya bila nilai toleransi variabel independent $<0,10$ serta nilai VIF $>10$ maka keputusannya terjadi multikolinearitas, yang artinya memiliki multikolinearitas antar variabel independennya atau dapat dikatakan tidak lolos uji (Ghozali, 2013; Wulansari, Titisari, \& Nurlaela, 2020).

\section{Uji Heteroskedastisitas}

Tujuan uji heteroskedastisitas adalah untuk menemukan apakah model regresi berbeda varians dari residual satu ke observasi yang lainnya. Hasil uji heteroskedastisitas terlihat melalui grafik scatterplot (Zulkarnain \& Ningrum, 2020). 


\section{Analisis Korelasi}

Analisis korelasi Pearson Product Moment bertujuan untuk mengetahui keeratan hubungan dan membuktikan hipotesis antara variabel independen dengan variabel dependen (Sugiyono, 2017; Kosasih, 2019).

Kriteria untuk mengetahui keeratan hubungan tersebut terlihat pada tabel 2 berikut ini:

Tabel 3. Pedoman Untuk Memberikan Interpretasi Terhadap Koefisien Korelasi

\begin{tabular}{cc}
\hline Interval Koefisien & Tingkat Hubungan \\
\hline $0,000-0,199$ & Sangat Rendah \\
$0,200-0,399$ & Rendah \\
$0,400-0,599$ & Sedang \\
$0,600-0,799$ & Kuat \\
$0,800-1,000$ & Sangat Kuat \\
\hline
\end{tabular}

(Sugiyono, 2017)

\section{Analisis Koefisen Determinasi}

Koefisien determinasi digunakan untuk mengetahui berapa besar kontribusi atau peranan variabel independen terhadap variabel dependen. Nilai koefisien determinasi merupakan nilai antara nol ataupun satu. Jika nilai yang diperoleh kecil berarti kemampuan variabel independen dalam menerangkan alterasi variabel dependen amat terbatas. Kebalikannya bila nilai yang mendekati 1 berarti variabel independen membagikan nyaris seluruh informasi yang diperlukan buat memprediksi berbagai variabel tersebut (Aditia, Wadud, \& Kurniawan, 2020).

\section{Analisis Regresi Berganda}

Analisis regresi adalah suatu analisis yang mengukur dampak antara variabel independen terhadap variabel dependen (Setyowati, 2019). Analisis ini digunakan untuk mengukur perubahan variabel dependen berdasarkan perubahan-perubahan variabel independen. Pada penelitian ini menggunakan regresi sederhana karena jumlah variabel bebas hanya satu dengan menggunakan model berikut:

$Y 1=a+b X$

Keterangan:

Y1 = Subjek variabel dependen

a = Harga $\mathrm{Y}$ bila $\mathrm{X}=0$ (harga konstan)

$\mathrm{b}=$ Angka arah atau koefisien regresi

$\mathrm{X}=$ Subjek pada variabel independen

\section{Hasil dan Pembahasan Uji Validitas}

Hasil uji validitas terlihat pada tabel 4, 5 dan 6 dibawah ini:
Tabel 4. Uji Validitas Instrumen Beban Kerja (X)

\begin{tabular}{cccc}
\hline Pernyataan & $\begin{array}{c}r \\
\text { Dengan } \\
\text { Rata- } \\
\text { Rata }\end{array}$ & $\begin{array}{c}\text { Nilai } \\
\text { Kritis }\end{array}$ & Keterangan \\
\hline 1 & 0.620 & 0.3 & Valid \\
2 & 0.516 & 0.3 & Valid \\
3 & 0.859 & 0.3 & Valid \\
4 & 0.690 & 0.3 & Valid \\
5 & 0.767 & 0.3 & Valid \\
6 & 0.583 & 0.3 & Valid \\
\hline
\end{tabular}

Nilai kritis ( $r$ ) di ambil dari tabel kritis 0,3 pada $n=120$ dan $\alpha 0,05(5 \%)$

Sumber: Data primer yang diolah, 2021.

Hasil uji validitas instrumen beban kerja (X) tersebut, terlihat bahwa responden dapat menjawab semua butir pernyataan. Dimana hasilnya dari pernyataan indikator dinyatakan valid sebanyak 6 item pernyataan, artinya hanya 6 pernyataan tersebut yang dapat mengukur apa yang hendak di ukur yaitu mengukur beban kerja.

Tabel 5. Uji Validitas Instrumen Prestasi Kerja (Variabel Y1)

\begin{tabular}{cccc}
\hline Pernyataan & $\begin{array}{c}r \\
\text { Dengan } \\
\text { Rata- } \\
\text { Rata }\end{array}$ & $\begin{array}{c}\text { Nilai } \\
\text { Kritis }\end{array}$ & Keterangan \\
\hline 1 & 0.433 & 0.3 & Valid \\
2 & 0.537 & 0.3 & Valid \\
3 & 0.833 & 0.3 & Valid \\
4 & 0.694 & 0.3 & Valid \\
5 & 0.804 & 0.3 & Valid \\
6 & 0.619 & 0.3 & Valid \\
7 & 0.502 & 0.3 & Valid \\
8 & 0.683 & 0.3 & Valid \\
9 & 0.587 & 0.3 & Valid \\
10 & 0.763 & 0.3 & Valid \\
11 & 0.607 & 0.3 & Valid \\
12 & 0.541 & 0.3 & Valid \\
\hline
\end{tabular}

Nilai kritis (r) di ambil dari tabel kritis 0,3 pada $n=120$ dan $\alpha 0,05$ (5\%)

Sumber: Data primer yang diolah, 2021.

Hasil uji validitas instrumen prestasi kerja (Y1) tersebut, terlihat bahwa responden dapat menjawab semua butir pernyataan. Dimana hasilnya dari pernyataan indikator dinyatakan valid sebanyak 12 item pernyataan, artinya hanya 12 pernyataan tersebut yang dapat mengukur apa yang hendak di ukur yaitu mengukur prestasi kerja. 
Tabel 6. Uji Validitas Instrumen Produktivitas Kerja (Y2)

\begin{tabular}{cccc}
\hline Pernyataan & $\begin{array}{c}r \\
\text { Dengan } \\
\text { Rata- } \\
\text { Rata }\end{array}$ & $\begin{array}{c}\text { Nilai } \\
\text { Kritis }\end{array}$ & Keterangan \\
\hline 1 & 0.381 & 0.3 & Valid \\
2 & 0.514 & 0.3 & Valid \\
3 & 0.828 & 0.3 & Valid \\
4 & 0.678 & 0.3 & Valid \\
5 & 0.825 & 0.3 & Valid \\
6 & 0.636 & 0.3 & Valid \\
7 & 0.528 & 0.3 & Valid \\
8 & 0.702 & 0.3 & Valid \\
9 & 0.596 & 0.3 & Valid \\
10 & 0.781 & 0.3 & Valid \\
11 & 0.608 & 0.3 & Valid \\
12 & 0.575 & 0.3 & Valid \\
\hline
\end{tabular}

Nilai kritis (r) di ambil dari tabel kritis 0,3 pada $n=120$ dan $\alpha 0,05(5 \%)$

Sumber: Data primer yang diolah, 2021.

Hasil uji validitas instrumen produktivitas kerja (Y2) tersebut, terlihat bahwa responden dapat menjawab semua butir pernyataan. Dimana hasilnya dari pernyataan indikator dinyatakan valid sebanyak 12 item pernyataan, artinya hanya 12 pernyataan tersebut yang dapat mengukur apa yang hendak di ukur yaitu mengukur produktivitas kerja.

\section{Uji Reliabilitas}

Tabel 7. Uji Reliabilitas Beban Kerja (X)

\begin{tabular}{r|r}
\multicolumn{2}{c}{ Reliability Statistics } \\
\hline $\begin{array}{c}\text { Cronbach's } \\
\text { Alpha }\end{array}$ & N of Items \\
\hline .722 & 6 \\
\hline
\end{tabular}

Sumber: Data primer yang diolah, 2021.

Hasil uji reliabilitas menunjukkan bahwa variabel beban kerja (X) diperoleh nilai Alpha Cronbach's $(\alpha)$ sebesar 0,722 artinya nilai reliabel berada diantara nilai $0,600>\alpha>0,800$ yang berarti instrumen variabel beban kerja cukup baik dan dapat dipercaya.

Tabel 8. Uji Reliabilitas Prestasi Kerja (Y1)

\begin{tabular}{r|r}
\multicolumn{2}{c}{ Reliability Statistics } \\
\hline $\begin{array}{c}\text { Cronbach's } \\
\text { Alpha }\end{array}$ & N of Items \\
\hline .851 & 12 \\
\hline
\end{tabular}

Sumber: Data primer yang diolah, 2021.

Hasil uji reliabilitas menunjukkan bahwa variabel prestasi kerja (Y1) diperoleh nilai Alpha Cronbach's $(\alpha)$ sebesar 0,851 artinya nilai reliabel sama dengan $\alpha>0,800$ yang berarti instrumen variabel prestasi kerja sangat baik.
Tabel 9. Uji Reliabilitas Produktivitas Kerja (Y2)

Reliability Statistics

\begin{tabular}{|c|c|}
\hline $\begin{array}{l}\text { Cronbach's } \\
\text { Alpha }\end{array}$ & $\mathrm{N}$ of Items \\
\hline .850 & 12 \\
\hline
\end{tabular}

Sumber: Data primer yang diolah, 2021.

Hasil uji reliabilitas menunjukkan bahwa variabel produktivitas kerja (Y2) diperoleh nilai Alpha Cronbach's ( $\alpha$ ) sebesar 0,850 artinya nilai reliabel sama dengan $\alpha>0,800$ yang berarti instrumen variabel prestasi kerja sangat baik.

\section{Uji Normalitas}

Uji normalitas grafik normal $P-P$ plot of regression standardized residual merupakan salah satu cara untuk menguji normalitas residual yang hasilnya ditampilkan sebagai berikut:

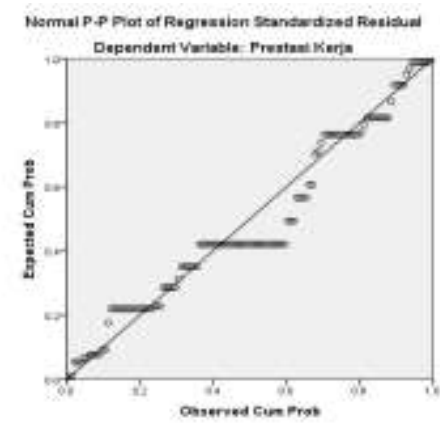

Sumber: Data primer yang diolah, 2021.

Gambar 1. Hasil Perhitungan Uji Normalitas Beban Kerja Terhadap Prestasi Kerja

Berdasarkan gambar 1 dapat disimpulkan bahwa grafik histogram memberikan pola distribusi yang normal. Sedangkan grafik normal P-P plot of regression standardized residual terlihat titik-titik menyebar disekitar garis diagonal serta penyebarannya mengikuti garis diagonalnya. Oleh karena itu, dapat disimpulkan bahwa dari gambar 1 tersebut menunjukkan bahwa model regresi layak digunakan karena memenuhi asumsi normalitas.

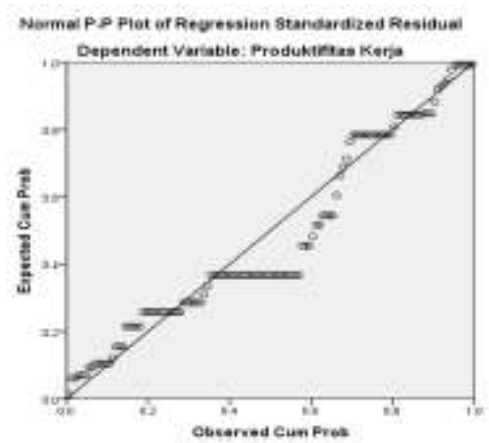

Sumber: Data primer yang diolah, 2021.

Gambar 2. Hasil Perhitungan Uji Normalitas Beban Kerja Terhadap Produktivitas Kerja 
Berdasarkan gambar 2 dapat disimpulkan bahwa grafik histogram memberikan pola distribusi yang normal. Sedangkan grafik normal $P-P$ plot of regression standardized residual terlihat titik-titik menyebar disekitar garis diagonal serta penyebarannya mengikuti garis diagonalnya. Oleh karena itu, dapat disimpulkan bahwa dari gambar 2 tersebut menunjukkan bahwa model regresi layak digunakan karena memenuhi asumsi normalitas.

\section{Uji Multikolinearitas}

Multikolinearitas bertujuan untuk menguji apakah model regresi ditemukan adanya korelasi antar variabel independen. Jika variabel bebas saling berhubungan maka variabel tersebut tidak ortogonal. Variabel ortogonal adalah variabel bebas, dimana nilai korelasi antar variabel bebas sama dengan nol..

Tabel 10. Hasil Uji Multikolinearitas Beban Kerja Terhadap Prestasi Kerja

Koefisien Collinearity Statistics

\begin{tabular}{cc}
\hline Toleransi & VIF \\
\hline 1,000 & 1,000
\end{tabular}

Sumber: Data primer yang diolah, 2021.

Berdasarkan tabel 10, dapat dilihat hasil uji multikolinieritas nilai tolerance variabel beban kerja $(\mathrm{X})=1,000$ lebih besar dari 0,10 (tolerance $>0,10)$, ini menunjukkan bahwa dalam penelitian ini tidak terdapat masalah dalam uji multikolinieritas. Demikian juga dengan nilai VIF variabel prestasi kerja $(\mathrm{Y} 1)=1,000$ lebih kecil dari 10,00 (VIF < 10,00), maka dapat disimpulkan bahwa tidak terjadi multikolinieritas antara variabel independen dalam model regresi (regression model).

Tabel 11. Hasil Uji Multikolinearitas Beban Kerja Terhadap Produktivitas Kerja

Koefisien Collinearity Statistics

\begin{tabular}{cc}
\hline Toleransi & VIF \\
\hline 1,000 & 1,000 \\
\hline
\end{tabular}

Sumber: Data primer yang diolah, 2021.

Berdasarkan tabel 11, dapat dilihat hasil uji multikolinieritas nilai tolerance variabel beban kerja $(\mathrm{X})=1,000$ lebih besar dari 0,10 (tolerance $>0,10)$, ini menunjukkan bahwa dalam penelitian ini tidak terdapat masalah dalam uji multikolinieritas. Demikian juga dengan nilai VIF variabel produktivitas kerja $(\mathrm{Y} 2)=1,000$ lebih kecil dari 10,00 ( VIF < 10,00), maka dapat disimpulkan bahwa tidak terjadi multikolinieritas antara variabel independen dalam model regresi (regression model).

Uji Heteroskedastisitas

Hasil uji heteroskedastisitas terlihat pada gambar 3 dan 4 dibawah ini:

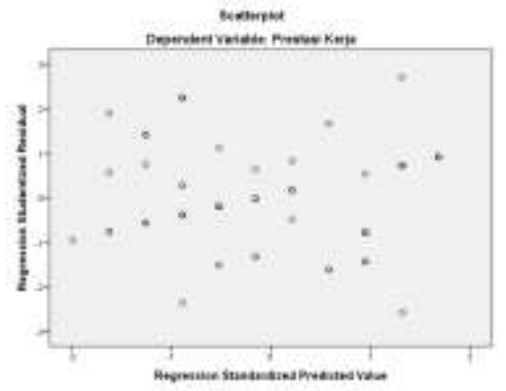

Sumber: Data primer yang diolah, 2021.

Gambar 3. Hasil Uji Heteroskedastisitas Beban Kerja Terhadap Prestasi Kerja

Berdasarkan gambar 3 dapat dilihat sebaran titik-titik yang acak, baik di atas maupun dibawah angka 0 dari sumbu Y, dapat disimpulkan tidak terjadi heteroskedastisitas dalam model regresi ini.

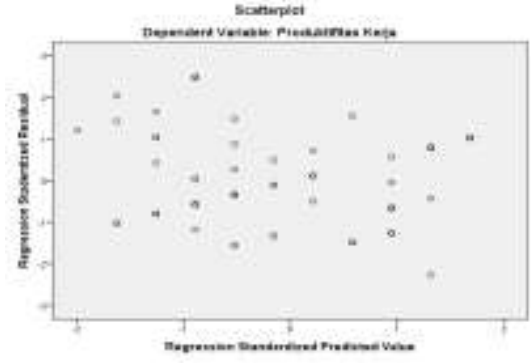

Sumber: Data primer yang diolah, 2021.

Gambar 4. Hasil Uji Heteroskedastisitas Beban Kerja Terhadap Produktivitas Kerja

Berdasarkan gambar 4 dapat dilihat sebaran titik-titik yang acak, baik di atas maupun dibawah angka 0 dari sumbu Y, dapat disimpulkan tidak terjadi heteroskedastisitas dalam model regresi ini.

\section{Analisis Korelasi Beban Kerja Terhadap Prestasi Kerja dan Produktivitas Kerja}

Hasil analisis korelasi terlihat pada tabel 12 dan 13 dibawah ini:

Tabel 12. Analisis Korelasi Beban Kerja terhadap Prestasi Kerja

\begin{tabular}{llrr}
\multicolumn{4}{c}{ Correlations } \\
\hline & $\begin{array}{c}\text { Beban } \\
\text { Kerja }\end{array}$ & \multicolumn{1}{c}{$\begin{array}{c}\text { Prestasi } \\
\text { Kerja }\end{array}$} \\
\hline Beban & Pearson & 1 & $.951^{* *}$ \\
Kerja & Correlation & & \\
& Sig. (2-tailed) & & .000 \\
& N & 120 & 120 \\
Prestasi & Pearson & $.951^{* *}$ & 1 \\
Kerja & Correlation & & \\
& Sig. (2-tailed) & .000 & 120 \\
& N & 120 & 120 \\
\hline$* *$ Correlation is significant at the 0.01 level (2- tailed).
\end{tabular}


Dapat dilihat pada tabel 12 nilai korelasi beban kerja (X) dengan prestasi kerja (Y1) sebesar $R=$ 0,951 yang berarti berada diantara nilai $0,800-1,000$, artinya memiliki hubungan yang sangat kuat dan searah. Sifat hubungan positif yang artinya jika beban kerja meningkat maka akan berpengaruh pada prestasi kerja.

Tabel 13. Analisis Korelasi Beban Kerja Terhadap Produktivitas Kerja

\begin{tabular}{llrr}
\hline \multicolumn{4}{c}{ Correlations } \\
& \multicolumn{1}{c}{$\begin{array}{c}\text { Produktifitas } \\
\text { Kerja }\end{array}$} & $\begin{array}{c}\text { Beban } \\
\text { Kerja }\end{array}$ \\
\hline $\begin{array}{l}\text { Pearson } \\
\text { Correlation }\end{array}$ & $\begin{array}{l}\text { Produktifitas } \\
\text { Kerja } \\
\text { Beban Kerja }\end{array}$ & 1.000 & .938 \\
Sig. (1-tailed) & $\begin{array}{l}\text { Produktifitas } \\
\text { Kerja }\end{array}$ & .938 & 1.000 \\
& $\begin{array}{l}\text { Beban Kerja } \\
\text { Produktifitas }\end{array}$ & .000 & .000 \\
& $\begin{array}{l}\text { Kerja } \\
\text { Beban Kerja }\end{array}$ & 120 & 120 \\
**. Correlation is significant at the 0.01 level (2-tailed). \\
Sumber: Data primer yang diolah, 2021.
\end{tabular}

Dapat dilihat nilai korelasi beban kerja $(\mathrm{X})$ dengan produktivitas kerja (Y2) sebesar $R=0,938$ yang berarti berada diantara nilai 0,800 - 1,000, artinya memiliki hubungan yang sangat kuat dan searah. Sifat hubungan positif yang artinya jika beban kerja meningkat maka akan berpengaruh pada produktivitas kerja.

\section{Analisis Koefisien Determinasi}

Hasil analisis koefisien determinasi terlihat pada tabel 14 dan 15 dibawah ini:

Tabel 14. Analisis Koefisien Determinasi $\left(\mathrm{R}^{2}\right)$ Beban Kerja Terhadap Prestasi Kerja

\begin{tabular}{|c|c|c|c|c|}
\hline \multicolumn{5}{|c|}{ Model Summary } \\
\hline Model & $\mathrm{R}$ & $\begin{array}{c}\mathrm{R} \\
\text { Square }\end{array}$ & $\begin{array}{c}\text { Adjusted R } \\
\text { Square }\end{array}$ & $\begin{array}{l}\text { Std. Error of the } \\
\text { Estimate }\end{array}$ \\
\hline 1 & $.951^{\mathrm{a}}$ & .904 & .903 & 1.53125 \\
\hline
\end{tabular}

Berdasarkan perhitungan tabel 14, maka dapat diketahui besarnya angka koefisien determinasi yaitu Adjusted $\mathrm{R}^{\text {Square }}$ sebesar 0,903 atau $90,3 \%$. Hal ini memberikan makna bahwa beban kerja (X) memberikan kontribusi pengaruh sebesar 90,3\% terhadap prestasi kerja (Y1) dan sisanya sebesar 9,7\% dipengaruhi oleh variabel lain yang tidak diteliti.

Tabel 15. Analisis Koefisien Determinasi $\left(\mathrm{R}^{2}\right)$ Beban Kerja Terhadap Produktivitas Kerja

\begin{tabular}{|c|c|c|c|c|}
\hline \multicolumn{5}{|c|}{ Model Summary } \\
\hline Model & $\mathrm{R}$ & $\begin{array}{c}\mathrm{R} \\
\text { Square }\end{array}$ & $\begin{array}{l}\text { Adjusted R } \\
\text { Square }\end{array}$ & $\begin{array}{l}\text { Std. Error of the } \\
\text { Estimate }\end{array}$ \\
\hline 1 & $.938^{\mathrm{a}}$ & .879 & .878 & 1.65077 \\
\hline
\end{tabular}

Berdasarkan perhitungan tabel 15, maka dapat diketahui besarnya angka koefisien determinasi yaitu Adjusted $\mathrm{R}^{\text {Square }}$ sebesar 0,878 atau $87,8 \%$. Hal ini memberikan makna bahwa beban kerja (X) memberikan kontribusi pengaruh sebesar $87,8 \%$ terhadap produktivitas kerja (Y2) dan sisanya sebesar $12,2 \%$ dipengaruhi oleh variabel lain yang tidak diteliti.

\section{Analisis Regresi Linier Berganda}

Hasil analisis regresi linier terlihat pada tabel 16 dan 17 dibawah ini:

Tabel 16. Analisis Regresi Linear Berganda Beban Kerja dan Prestasi Kerja

\begin{tabular}{|c|c|c|c|c|c|}
\hline \multicolumn{6}{|c|}{ Coefficients $^{a}$} \\
\hline \multirow[b]{2}{*}{ Model } & $\begin{array}{r}\text { Unstan } \\
\text { Coef }\end{array}$ & $\begin{array}{l}\text { dardized } \\
\text { icients }\end{array}$ & $\begin{array}{c}\text { Standardized } \\
\text { Coefficients }\end{array}$ & \multirow[b]{2}{*}{$\mathrm{t}$} & \multirow[b]{2}{*}{ Sig. } \\
\hline & B & $\begin{array}{l}\text { Std. } \\
\text { Error }\end{array}$ & Beta & & \\
\hline 1 (Constant) & 7.029 & 1.317 & & 5.337 & .000 \\
\hline $\begin{array}{l}\text { Beban } \\
\text { kerja }\end{array}$ & 1.720 & .052 & .951 & 33.378 & .000 \\
\hline
\end{tabular}

Sumber: Data primer yang diolah, 2021.

Berdasarkan tabel 16 diperoleh konstanta (a) 7,029 sedangkan nilai koefisien regresi beban kerja sebesar 1,720 sehingga dengan demikian persamaan regresinya dapat ditulis:

$$
\begin{gathered}
\mathrm{Y}=7,029+1,720 \mathrm{X} \\
\mathrm{Y}=8,749
\end{gathered}
$$

Berdasarkan persamaan regresi tersebut dapat diterjemahkan:

1. Konstanta (a) memiliki nilai sebesar 7,029, menyatakan bahwa jika beban kerja (X) tidak ada kenaikan atau sama dengan nilai 0 , maka besarnya nilai prestasi kerja (Y1) sebesar 7,029.

2. Nilai koefisien regresi beban kerja (X) adalah sebesar 1,720 dan bertanda positif, artinya jika variabel beban kerja meningkat sebesar 1 poin, maka akan menyebabkan nilai prestasi kerja meningkat sebesar 1,720 poin. Ini menunjukan bahwa beban kerja memiliki hubungan searah dengan prestasi kerja.

Tabel 17. Analisis Regresi Linear Berganda Beban Kerja dan Produktivitas Kerja

\begin{tabular}{|c|c|c|c|c|c|}
\hline \multirow[b]{2}{*}{ Model } & \multicolumn{2}{|c|}{$\begin{array}{c}\text { Unstandardized } \\
\text { Coefficients }\end{array}$} & \multirow{2}{*}{$\begin{array}{c}\begin{array}{c}\text { Standardized } \\
\text { Coefficients }\end{array} \\
\text { Beta }\end{array}$} & \multirow[b]{2}{*}{$\mathrm{t}$} & \multirow[b]{2}{*}{ Sig. } \\
\hline & B & $\begin{array}{l}\text { Std. } \\
\text { Error }\end{array}$ & & & \\
\hline 1 (Constant) & 9.492 & 1.420 & & 6.685 & .000 \\
\hline $\begin{array}{l}\text { Beban } \\
\text { kerja }\end{array}$ & 1.628 & .056 & .938 & 29.306 & .000 \\
\hline
\end{tabular}

Coefficients $^{\mathrm{a}}$

Sumber: Data primer yang diolah, 2021. 
Berdasarkan tabel 17 diperoleh konstanta (a) adalah 9,492 sedangkan nilai koefisien regresi beban kerja sebesar 1,628 sehingga dengan demikian persamaan regresinya dapat ditulis:

$$
\begin{gathered}
\mathrm{Y}=9,492+1,628 \mathrm{X} \\
\mathrm{Y}=11,120
\end{gathered}
$$

Berdasarkan persamaan regresi tersebut dapat diterjemahkan:

1. Konstanta (a) memiliki nilai sebesar 9,492 menyatakan bahwa jika beban kerja (X) tidak ada kenaikan atau sama dengan nilai 0 , maka besarnya nilai produktivitas kerja (Y2) sebesar 9,492.

2. Nilai koefisien regresi variabel beban kerja (X) adalah sebesar 1,628 dan bertanda positif, artinya jika variabel beban kerja meningkat sebesar 1 poin, maka akan menyebabkan nilai produktivitas kerja meningkat sebesar 1,628 poin. Ini menunjukan bahwa beban kerja memiliki hubungan searah dengan produktivitas kerja.

\section{Uji t}

Hasil uji $\mathrm{t}$ dampak beban kerja terhadap prestasi kerja dapat dilihat pada tabel 18 dibawah ini:

Tabel 18. Uji t Dampak Beban Kerja Terhadap Prestasi Kerja

\begin{tabular}{|c|c|c|c|c|c|}
\hline \multirow[b]{2}{*}{ Model } & \multicolumn{2}{|c|}{$\begin{array}{c}\text { Unstandardized } \\
\text { Coefficients }\end{array}$} & $\begin{array}{c}\text { Standardized } \\
\text { Coefficients } \\
\end{array}$ & \multirow[b]{2}{*}{$\mathrm{t}$} & \multirow[b]{2}{*}{ Sig. } \\
\hline & B & $\begin{array}{l}\text { Std. } \\
\text { Error }\end{array}$ & Beta & & \\
\hline 1 (Constant) & 7.029 & 1.317 & & 5.337 & .000 \\
\hline $\begin{array}{l}\text { Beban } \\
\text { Kerja }\end{array}$ & 1.720 & .052 & .951 & 33.378 & .000 \\
\hline
\end{tabular}

Coefficients $^{\mathrm{a}}$

Dari tabel 18 dapat diketahui bahwa beban kerja memiliki signifikansi $0,000<0,05$ lebih kecil (sig. $<\alpha$ ) dengan taraf signifikan 0,05 , dan atau thitung $>\mathrm{t}_{\text {tabel }}$ dengan $n-k(120-2)$, sehingga diperoleh $33,378>1,658$ dengan taraf signifikansi 0,05 maka dapat disimpulkan bahwa $\mathrm{H}_{0}$ ditolak dan $\mathrm{H}_{1}$ diterima. Ini artinya bahwa terdapat dampak yang signifikan dari beban kerja terhadap prestasi kerja.

Hasil uji t dampak beban kerja terhadap produktivitas kerja dapat dilihat pada tabel 19 dibawah ini:

Tabel 19. Uji t Dampak Beban Kerja Terhadap Produktivitas Kerja

\begin{tabular}{|c|c|c|c|c|c|}
\hline \multirow[b]{2}{*}{ Model } & \multicolumn{2}{|c|}{$\begin{array}{c}\text { Unstandardized } \\
\text { Coefficients }\end{array}$} & \multirow{2}{*}{$\begin{array}{c}\text { Standardized } \\
\text { Coefficients } \\
\text { Beta }\end{array}$} & \multirow[b]{2}{*}{$\mathrm{t}$} & \multirow[b]{2}{*}{ Sig. } \\
\hline & $\mathrm{B}$ & $\begin{array}{l}\text { Std. } \\
\text { Error }\end{array}$ & & & \\
\hline 1 (Constant) & 9.492 & 1.420 & & 6.685 & .000 \\
\hline $\begin{array}{l}\text { Beban } \\
\text { Kerja }\end{array}$ & 1.628 & .056 & .938 & 29.306 & .000 \\
\hline
\end{tabular}

Coefficients $^{a}$
Dari tabel 19 dapat diketahui bahwa beban kerja memiliki signifikansi $0,000<0,05$ lebih kecil (sig. $<\alpha$ ) dengan taraf signifikan 0,05 , dan atau thitung $>\mathrm{t}_{\text {tabel }}$ dengan $n-k(96-2)$, sehingga diperoleh 29,306 > 1,658 dengan taraf signifikansi 0,05 maka dapat disimpulkan bahwa $\mathrm{H}_{0}$ ditolak dan $\mathrm{H}_{1}$ diterima. Ini artinya bahwa terdapat dampak yang signifikan dari beban kerja terhadap produktivitas kerja.

Jadi dapat disimpulkan bahwa secara parsial beban kerja berpengaruh positif dan signifikan terhadap prestasi kerja dan produktivitas kerja. Kesimpulan ini diperkuat oleh penelitian dari (Inegbedion, Inegbedion, Peter, \& Harry, 2020), dimana hasil penelitiannya menyimpulkan bahwa persepsi beban kerja yang adil mampu meningkatkan kepuasan kerja sedangkan persepsi beban kerja yang tidak adil mempengaruhi kepuasan kerja dan sangat merugikan. Dengan kata lain persepsi karyawan tentang beban kerja dapat mempengaruhi prestasi dan produktivitas kerja yang mengakibatkan kepuasan kerja pada karyawan.

\section{Uji F}

Hasil uji F dampak beban kerja terhadap prestasi kerja dapat dilihat pada tabel 20 dibawah ini:

Tabel 20. Uji F Dampak Beban Kerja Terhadap Prestasi Kerja

\begin{tabular}{|c|c|}
\hline Nilai F & Signifikansi \\
\hline 1114,119 & 0,000 \\
\hline
\end{tabular}

Koefisien Uji F

Sumber: Data primer yang diolah, 2021.

Berdasarkan tabel 20 dapat diketahui bahwa signifikansi $0,000<0,05$ dan $F_{\text {hitung }}>F_{\text {tabel }}$ dengan df $(\mathrm{n} 1)=v-1$ dan df $(\mathrm{n} 2)=\mathrm{n}-\mathrm{k}$. Sehingga 1114,119> 3,07, maka $\mathrm{H}_{0}$ ditolak dan $\mathrm{H}_{1}$ diterima. Artinya ada dampak signifikan antara beban kerja terhadap prestasi kerja secara simultan.

Hasil uji F dampak beban kerja terhadap produktivitas kerja dapat dilihat pada tabel 21 dibawah ini:

Tabel 21. Uji F Dampak Beban Kerja Terhadap Produktivitas Kerja Koefisien Uji F

\begin{tabular}{cc}
\hline Nilai F & Signifikansi \\
\hline 858,817 & 0,000 \\
\hline
\end{tabular}

Sumber: Data primer yang diolah, 2021.

Berdasarkan tabel 21 dapat diketahui bahwa signifikansi $0,000<0,05$ dan $F_{\text {hitung }}>F_{\text {tabel }}$ dengan df $(\mathrm{n} 1)=v-1$ dan df $(\mathrm{n} 2)=\mathrm{n}-\mathrm{k}$. Sehingga 858,817> 3,07, maka $\mathrm{H}_{0}$ ditolak dan $\mathrm{H}_{1}$ diterima. Artinya ada dampak signifikan antara beban kerja terhadap produktivitas kerja secara simultan.

Hasil ini diperkuat dari penelitian (Soelton, Hardianti, Kuncoro, \& Jumadi, 2020) yang menunjukkan bahwa beban kerja memiliki dampak 
positif dan signifikan terhadap burnout sehingga mengakibatkan efek berantai terhadap prestasi dan produktivitas kerja karyawan. Beban kerja berlebih merupakan salah satu masalah yang sering dialami oleh karyawan, tuntutan pekerjaan yang terkait dengan sektor aktivitas apa pun atau setiap kategori sosial-profesional dapat menyebabkan masalah kesehatan (Coupaud, 2017) yang pada akhirnya akan mempengaruhi prestasi dan produktivitas kerja.

\section{Kesimpulan}

Hasil penelitian menunjukkan bahwa beban kerja memberikan dampak secara parsial masingmasing terhadap prestasi dan produktivitas kerja. Selain itu beban kerja juga memberikan pengaruh secara simultan terhadap prestasi kerja dan produktivitas kerja. Ini terlihat dari target penjualan bulanan selama tahun 2020 banyak yang tidak tercapai, artinya beban kerja karyawan pada tahun 2020 sangat berat sehingga mempengaruhi prestasi dan produktivitas kerja. Hal ini dapat dimaklumi, karena yang membuat target penjualan tidak tercapai salah satunya adalah dari awal tahun 2020 pandemi Covid-19 merebak di seluruh dunia, termasuk Indonesia, hingga membuat laju perekonomian menjadi terhambat yang mengakibatkan daya beli masyarakat menjadi menurun, sedangkan beban kerja karyawan tetap.

Bagi pihak manajemen perusahaan, penelitian ini dapat dijadikan rujukan untuk menetapkan target penjualan dan menerapkan kebijakan yang tepat bagi beban kerja karyawan pada periode yang akan datang. Selain itu untuk kesempurnaan penelitian dengan tema yang sama, dapat menelaah dan mengembangkan lagi dari variabel-variabel lainnya yang berpengaruh terhadap prestasi dan produktivitas kerja karyawan selain faktor beban kerja.

\section{Referensi}

Aditia, A. R. R., Wadud, M., \& Kurniawan, M. (2020). Pengaruh Kualitas Produk terhadap Kepuasan Konsumen Sepeda Motor NMAX pada PT Yamaha A. Rivai Palembang. Jurnal Nasional Manajemen Pemasaran \& SDM, 1(01), 23-37. https://doi.org/10.47747/jnmpsdm.v1i01.4

Ariani, D. R., Ratnasari, S. L., \& Tanjung, R. (2020). Pengaruh Rotasi Jabatan, Disiplin Kerja dan Beban Kerja Terhadap Produktivitas Kerja Karyawan. Jurnal Dimensi, 9(3), 480-493.

Arifin, Z. (2017). Kriteria Instrumen Dalam Suatu Penelitian. Jurnal Theorems (The Original Research of Mathematics), 2(1), 28-36. https://doi.org/http://dx.doi.org/10.31949/th.v2i1. 571

Borghini, G., Astolfi, L., Vecchiato, G., Mattia, D., \& Babiloni, F. (2014). Measuring neurophysiological signals in aircraft pilots and car drivers for the assessment of mental workload, fatigue and drowsiness. Neuroscience and
Biobehavioral Reviews, 44, 58-75. https://doi.org/10.1016/j.neubiorev.2012.10.003

Coupaud, M. (2017). Determinants of health at work in the EU15: elaboration of synthetic indicators of working conditions and their impacts on the physical and mental health of workers. International Journal of Manpower, 38(1). https://doi.org/https://doi.org/10.1108/IJM-022016-0040

Elvina. (2020). Pengaruh Aktualisasi Diri dan Beban Kerja Terhadap Prestasi Kerja Pegawai Dinas Pekerjaan Umum dan Penataan Ruang Kabupaten Labuhanbatu Utara. Ekonomi Bisnis Manajemen Dan Akuntansi (EBMA), 1(1), 25-32.

Ghozali, I. (2013). Aplikasi Analisis Multivariat dengan Program IBM SPSS 21 Update PLS Regresi. Semarang: Badan Penerbit Universitas Diponegoro.

Gilson, N., Straker, L., \& Parry, S. (2012). Occupational sitting: practitioner perceptions of health risks, intervention strategies and influences. Health Promotion Journal of Australia, 23(3), 208-212. https://doi.org/https://doi.org/10.1071/HE12208

Golden, L. (2012). The effects of working time on productivity and firm performance, research synthesis paper. International Labor Organization (ILO) Conditions of Work and Employment Series, 33.

Hsu, C. F., Propp, L., Panetta, L., Martin, S., Dentakos, S., Toplak, M. E., \& Eastwood, J. D. (2018). Mental effort and discomfort: Testing the peak-end effect during a cognitively demanding task. PLoS ONE, 13(2), 1-17. https://doi.org/10.1371/journal.pone.0191479

Inegbedion, H., Inegbedion, E., Peter, A., \& Harry, L. (2020). Perception of workload balance and employee job satisfaction in work organisations. Heliyon, 6(1), e03160. https://doi.org/10.1016/j.heliyon.2020.e03160

Ismunarti, D. H., Zainuri, M., Sugianto, D. N., \& Saputra, S. W. (2020). Pengujian Reliabilitas Instrumen Terhadap Variabel Kontinu Untuk Pengukuran Konsentrasi Klorofil- A Perairan. Buletin Oseanografi Marina, 9(1), 1-8. https://doi.org/10.14710/buloma.v9i1.23924

James, J. M., Rayner, A., \& Bruno, J. (2015). Are You My Mentor? New Perspectives and Research on Informal Mentorship. Journal of Academic Librarianship, 41(5), 532-539. https://doi.org/10.1016/j.acalib.2015.07.009

Jaw, C., Po-Hsun Hsiao, J., Huan, T.-C. (T. C. ., \& Woodside, A. G. (2016). Complexity Theory and Human Resources Management: Transcending Variable and Case-Based Perspectives of Service Employees' (Un)Happiness and Work Performance. Bad to Good. 
https://doi.org/10.1108/978-1-78635-334420161011

Koopmans, L., Bernaards, C. M., Hildebrandt, V. H., Schaufeli, W. B., De Vet Henrica, C. W., \& Van Der Beek, A. J. (2011). Conceptual frameworks of individual work performance: A systematic review. Journal of Occupational and Environmental Medicine, 53(8), 856-866. https://doi.org/10.1097/JOM.0b013e318226a763

Kosasih. (2019). Analisis Hubungan Biaya Pengembangan Dengan Laba Bersih di PT Industri Telekomunikasi Indonesia. JRB-Jurnal Riset Bisnis, 2(2), 125-136. https://doi.org/10.35592/jrb.v2i2.405

Laihonen, H., Jääskeläinen, A., Lönnqvist, A., \& Ruostela, J. (2012). Measuring the productivity impacts of new ways of working. Journal of Facilities Management, 10(2), 102-113. https://doi.org/10.1108/14725961211218749

Noor, Z. Z. (2020). The Model of Experiental Marketing, Service Quality, and Customer Loyalty. Journal of Talent Development and Excellence, 12(1), 192-199.

Palvalin, M. (2019). What matters for knowledge work productivity? Employee Relations, 41(1), 209-227. https://doi.org/10.1108/ER-04-20170091

Reza, H. K., Nugroho, S. H., \& Indonesia, J. (2020). The Assessment of Work Performance, Education , and Self Motivation on Organizational Citizenship Behavior. International Journal of Advanced Science and Technology, 29(03), 8019-8030.

Riyanto, A. (2019). Aspek Kepemimpinan Dan Kompetensi Aparatur Birokrasi Serta Dampaknya Terhadap Peningkatan Kinerja. Jurnal Ecodemica: Jurnal Ekonomi, Manajemen, Dan Bisnis, 3(2), 207-217. https://doi.org/10.31311/jeco.v3i2.6320

Rosen, M. A., Dietz, A. S., Lee, N., Jeng Wang, I., Markowitz, J., Wyskiel, R. M., ... Pronovost, P. J. (2018). Sensor-based measurement of critical care nursing workload: Unobtrusive measures of nursing activity complement traditional task and patient level indicators of workload to predict perceived exertion. PLoS ONE, 13(10), 1-16. https://doi.org/10.1371/journal.pone.0204819

Sari, A. Q., Sukestiyarno, Y. L., \& Agoestanto, A. (2017). Batasan Prasyarat Uji Normalitas Dan Uji Homogenitas Pada Model Regresi Linear. Unnes Journal of Mathematics, 6(2), 168-177. https://doi.org/10.15294/ujm.v6i2.11887

Setyowati, D. H. (2019). Pengaruh Efisiensi Operasional Terhadap Return on Assets Pada Bank Umum Syariah Di Indonesia. Masharif AlSyariah: Jurnal Ekonomi Dan Perbankan
Syariah, 4(2), 39-53. https://doi.org/http://dx .doi.org/10.30651/jms.v4i2.2635

Soelton, M., Hardianti, D., Kuncoro, S., \& Jumadi, J. (2020). Factors Affecting Burnout in Manufacturing Industries. In 4th International Conference on Management, Economics and Business (ICMEB 2019) (Vol. 120, pp. 46-52). Atlantis Press. https://doi.org/10.2991/aebmr.k.200205.010

Sugiyono. (2017). Metode Penelitian Kuantitatif Kualitatif dan R\&D. Bandung: Alfabeta.

Sunarsi, D. (2020). The Analysis of The Work Environmental and Organizational Cultural Impact on The Performance and Implication of The Work Satisfaction. Jurnal Ilmiah Ilmu Administrasi Publik, 9(2), 237-246.

Utami, R. S., \& Magdalena, M. (2020). Pengaruh Kebutuhan Aktualisasi Diri Dan Beban Kerja Terhadap Prestasi Kerja Karyawan Pada Dinas Perindustrian dan Perdagangan Sumatera Barat. Retrieved from https://osf.io/kdyca/

Vashti, H., \& Antonio, T. (2021). The Role of Price Promotion and Product Quality in Influencing the Intention to Repurchase Cok-Kis Cookies. KnE Social Sciences, 2021, 441-459. https://doi.org/10.18502/kss.v5i5.8831

Wahyuningrum, C. C. S. (2020). Pengaruh Event Marketing Terhadap Pengambilan Keputusan Berkuliah yang Di Mediasi oleh Brand Image (Studi Kasus Pada Mahasiswa Angkatan 2018 STIE PGRI Dewantara Jombang). Diss. STIE PGRI Dewantara.

Wulansari, T. A., Titisari, K. H., \& Nurlaela, S. (2020). Pengaruh Leverage, Intensitas Persediaan, Aset Tetap, Ukuran Perusahaan, Komisaris Independen Terhadap Agresivitas Pajak. JAE (Jurnal Akuntansi Dan Ekonomi), 5(1), 69-76. https://doi.org/https://doi.org/10.29407/jae.v5i1.1 4141

Yei-Yu Yeh, \& Wickens, C. D. (1988). Dissociation of performance and subjective measures of workload. Human Factors, 30(1), 111-120. https://doi.org/10.1177/001872088803000110

Yusup, F. (2018). Uji Validitas Dan Reliabilitas Instrumen Penelitian Kuantitatif. Tarbiyah: Jurnal Ilmiah Kependidikan, 7(1), 17-23. https://doi.org/http://dx.doi.org/10.18592/tarbiya h.v7i1.2100

Zulkarnain, \& Ningrum, D. A. (2020). Determinan Kualitas Laporan Keuangan Pemerintah Daerah Kota Sukabumi. Syntax Literate; Jurnal Ilmiah Indonesia, 5(5), 197-211. https://doi.org/http://dx.doi.org/10.36418/syntaxliterate.v5i5.1161 